\title{
Comprehensive coagulation and fibrinolytic potential in the acute phase of pediatric patients with idiopathic nephrotic syndrome evaluated by whole blood-based rotational thromboelastometry
}

\author{
Tomoaki Ishikawa $^{1} \cdot$ Yuto Nakajima $^{1,2} \cdot$ Takashi Omae $^{1} \cdot$ Kenichi Ogiwara $^{1} \cdot$ Keiji Nogami $^{1} \mathbb{D}$
}

Received: 17 June 2021 / Revised: 9 November 2021 / Accepted: 9 November 2021 / Published online: 8 January 2022

(c) The Author(s), under exclusive licence to International Pediatric Nephrology Association 2021

\begin{abstract}
Background Venous thromboembolism is a rare, serious complication of idiopathic nephrotic syndrome (INS) in childhood. The mechanisms responsible for the hypercoagulable state in the acute phase of INS are poorly understood, however. This study aimed to assess overall coagulation and fibrinolytic function in pediatric patients with INS.

Methods Global coagulation and fibrinolysis were examined in whole blood samples from 22 children with initial onset INS (initial-group), 22 children with relapsed INS (relapse-group), and 15 control pediatric patients using rotational thromboelastometry (ROTEM®). In the initial-group, blood samples were obtained before (week 0) and 1-4 weeks after initiation of corticosteroid therapy. EXTEM and FIBTEM were used to assess coagulation and fibrinolysis, respectively. Clot time (CT), clot formation time (CFT), maximum clot firmness (MCF), and $\alpha$-angle were determined as coagulation parameters, and lysis index at 30 and $60 \mathrm{~min}$ (LI30 and LI60, respectively) were assessed as fibrinolytic parameters.

Results CT was significantly shortened, and MCF and $\alpha$-angle were significantly greater than controls at week 0 and week 1 both in the initial-group and the relapse-group. MCF correlated with serum albumin $(r=0.70, p<0.001)$ and fibrinogen level $(r=0.68, p<0.001)$. The fibrinolytic parameters (LI30 and LI60) in the initial-group were stable and higher than those in controls at all time points $(p<0.01)$.

Conclusions We have shown that the hypofibrinolytic defect did not improve with effective NS treatment at the early 4-week time-point. Additionally, a likely pre-thrombotic state was evident in the period before initial onset and 1 week after corticosteroid therapy in pediatric INS.
\end{abstract}

Keywords Idiopathic nephrotic syndrome $\cdot$ Rotational thromboelastometry $\cdot$ Fibrinolysis $\cdot$ Hypercoagulability $\cdot$ Children

\section{Introduction}

Nephrotic syndrome (NS) is the most common glomerular disease in children, characterized by massive proteinuria, serum hypoalbuminemia, and edema. Venous thromboembolism (VTE) and serious complications including cerebral venous sinus thrombosis and pulmonary thromboembolism have been reported in approximately $3 \%$ of pediatric NS [1-12]. The mechanism(s) that cause VTE in NS remains to

Keiji Nogami

roc-noga@naramed-u.ac.jp

1 Department of Pediatrics, Nara Medical University, 840 Shijo-cho, Kashihara, Nara 634-8522, Japan

2 Advanced Medical Science of Thrombosis and Hemostasis, Nara Medical University, Kashihara, Nara, Japan be elucidated, however, and the establishment of prophylactic antithrombotic therapy could be highly beneficial.

Previous studies have suggested that the hypercoagulable state in NS patients is not associated with any single pathology but appears to be governed by multiple factors such as coagulation-related and/or fibrinolysis-related disturbances, hemoconcentration, acceleration of platelet function, and drug-related events including corticosteroid (CS) therapy and diuretics [1, 3, 5, 13, 14]. Nevertheless, among these etiologies, imbalances in coagulation and fibrinolysis are considered to be the primary triggers of VTE $[1,3,4]$. Changes in blood concentrations of relevant clotting proteins may reflect the sum of clearance, involving, for example, leakage into urine and synthesis in the liver. In particular, the important changes in plasma hemostatic protein, including high concentrations of fibrinogen and low levels of antithrombin, are known to be associated with hypercoagulability of NS 
[1], although few studies have assessed coagulation-fibrinolysis potential in whole blood samples from patients with NS.

Rotational thromboelastometry (ROTEM $®$ ) is a computerized, viscoelastic test, which examines the global coagulation process in whole blood from the beginning of clot formation to the conclusion of fibrinolysis in real-time [15-17]. ROTEM has been widely used as a point-of-care tool to evaluate comprehensive coagulation and fibrinolysis in various clinical circumstances including pregnancy, postsurgery, trauma/injury, and hemorrhagic and thrombotic disorders [17-23]. In addition, recent reports demonstrated that ROTEM was useful for assessing hypercoagulability in canine models of protein-losing nephropathies, rodent models with NS, and adult patients with different pathologic characteristics of NS [24-26]. There is little information, however, assessing clot formation and subsequent lysis by ROTEM in pediatric idiopathic NS (INS). The present study was designed, therefore, to investigate comprehensive coagulation and fibrinolytic potentials in whole blood samples from pediatric patients with INS using the automated ROTEM technique.

\section{Materials and methods}

The present study was approved by the Medical Research Ethics Committee of Nara Medical University (No.2365). Blood samples were obtained after informed consent according to the ethical guidelines of Nara Medical University.

\section{Patients}

Forty-four children with INS participated in the present study. Twenty-two children were initial onset INS (termed as the initial group), and 22 children were relapsed cases (termed as the relapse group). All patients were admitted to Nara Medical University Hospital between August 2016 and December 2020. In the initial group, the diagnosis of NS was defined as proteinuria $>40 \mathrm{mg} / \mathrm{m}^{2} / \mathrm{h}$ or urinary protein to creatinine ratio (UP/Cr) $\geq 200 \mathrm{mg} / \mathrm{mmol}(2 \mathrm{mg} /$ $\mathrm{mg}$ ) on a first morning urine sample, and hypoalbuminemia $(<2.5 \mathrm{~g} / \mathrm{dL})$ according to the International Study of Kidney Disease in Children [27]. Patients in the initial group received high-dose prednisolone at a dose of $60 \mathrm{mg} / \mathrm{m}^{2} /$ day for 4 weeks (max. $60 \mathrm{mg} /$ day). Relapse was defined in patients with a urine dipstick $\geq 3+$ on 3 consecutive days or $\mathrm{UP} / \mathrm{Cr} \geq 200 \mathrm{mg} / \mathrm{mmol}(2 \mathrm{mg} / \mathrm{mg})$ on a first morning urine sample [28]. Patients in relapse group received prednisolone at a dose of $60 \mathrm{mg} / \mathrm{m}^{2} /$ day (max. $60 \mathrm{mg} /$ day) until 3 days after complete remission was achieved. Complete remission was defined as UP/Cr (based on first morning void or $24 \mathrm{~h}$ urine sample $) \leq 20 \mathrm{mg} / \mathrm{mmol}(0.2 \mathrm{mg} / \mathrm{mg})$ or negative or trace dipstick on three or more consecutive occasions.
Steroid sensitive was defined as complete remission within 4 weeks of prednisone at standard dose $\left(60 \mathrm{mg} / \mathrm{m}^{2} /\right.$ day, max. $60 \mathrm{mg} /$ day) according to IPNA clinical practice recommendations [28].

Exclusion criteria included the use of anticoagulant or antiplatelet drugs, and other therapy such as ciclosporin that might influence coagulation, from 2 weeks before the onset of INS to the end of blood collection, and the use of CS within 2 weeks prior to the onset of INS. In addition, patients having any signs of secondary NS and who were aged $<1$ year at onset were considered congenital NS and were excluded. At the onset of NS, none of them had hypertension, hypocomplementemia, kidney insufficiency or hematuria ( $>20$ erythrocytes/high-power field) for which a kidney biopsy is recommended.

\section{Controls}

A control group matched for age and gender was selected from patients attending our hospital. The inclusion criteria for controls were as follows: (i) male or female aged 1-18 years old, (ii) no kidney and liver insufficiency, (iii) no proteinuria, (iv) no history of thrombosis and coagulation disorders, (v) no medication that may have affected coagulation at the time of sample collection.

\section{Blood samples}

Blood samples were taken from the 44 pediatric patients with INS and 15 pediatric control patients. Blood samples were obtained from the initial and relapse groups by venipuncture at the onset of INS just before CS therapy (termed $0 \mathrm{~W}$ in initial group). In addition, whole blood samples were obtained at four time-points (1, 2, 3, and 4 weeks) after CS therapy (termed as $1 \mathrm{~W}, 2 \mathrm{~W}, 3 \mathrm{~W}$, and $4 \mathrm{~W}$, respectively) in the initial group. Control blood samples were obtained by venipuncture when the patient was visiting our hospital under healthy conditions. Whole blood samples were collected into plastic tubes containing $3.2 \%$ sodium citrate at a ratio of 9:1 (Fuso Pharmaceutical Industries, Osaka, Japan).

\section{Conventional laboratory tests}

The following general laboratory data were recorded; hemoglobin $(\mathrm{Hb})$, hematocrit $(\mathrm{Ht})$, platelet counts (Plt), serum total protein (TP) and albumin (Alb), urinary total protein/ creatinine (UP/Cr). Coagulation parameters, including prothrombin time-international normalized ratio (PT-INR), activated partial thromboplastin time (APTT), fibrinogen, antithrombin (AT), fibrinogen/fibrin degradation products (FDP), D-dimer, plasminogen, $\alpha 2$-plasmin inhibitor $(\alpha 2 \mathrm{PI})$, thrombin-antithrombin complex (TAT), plasmin$\alpha 2$ PI-complex (PIC), total plasminogen activator inhibitor-1 
(tPAI-1) were estimated using standard commercially available methods.

\section{ROTEM}

ROTEM was performed using ROTEM delta (Tem Innovations $\mathrm{GmbH}$, Munich, Germany). Citrated whole blood samples were incubated for $30 \mathrm{~min}$ at $22{ }^{\circ} \mathrm{C}$, followed by ROTEM, using two alternative-triggered tests (EXTEM and FIBTEM) [17, 18].

(i) EXTEM (triggered by tissue factor and $\mathrm{Ca}^{2+}$ )-Coagulation interactions were initiated by the addition of $20 \mu \mathrm{L} \mathrm{CaCl}$ (final concentration (f.c.) $12.5 \mathrm{mM}$ ) together with $2.5 \mu \mathrm{L}$ tissue factor (TF; f.c. 0.5 pM, Innovin ${ }^{\circledR}$; Dade Behring, Marburg, Germany) to the citrated whole blood samples (280 $\mu \mathrm{L})$. Figure $1 \mathrm{~A}$ illustrates a representative thromboelastogram pattern of clot formation with the four measured parameters. The clotting time (CT) was estimated as the time from the start of the test until reaching $2 \mathrm{~mm}$ amplitude. The clot formation time (CFT) was determined as the time between 2 and $20 \mathrm{~mm}$ amplitude. The $\alpha$-angle was defined as the angle between the baseline and a tangent to the clotting curve through the $2 \mathrm{~mm}$ time point. The maximum clot firmness (MCF) was defined as the maximum amplitude observed.

(ii) FIBTEM (triggered by $\mathrm{TF}$, tPA, and $\mathrm{Ca}^{2+}$ )-Fibrinolytic responses were assessed after the addition of $20 \mu \mathrm{L} \mathrm{CaCl}$ (f.c. $12.5 \mathrm{mM}$ ), 2.5 $\mu \mathrm{L}$ TF (f.c. $0.5 \mathrm{pM}$ ), and $2.5 \mu \mathrm{L}$ tPA (f.c. $2 \mathrm{nM}$ ) to the citrated whole blood samples $(280 \mu \mathrm{L})$. Figure 1B illustrates a representative thromboelastogram pattern of clot lysis with the two specific parameters. The lysis index was determined as the residual clot firmness amplitude at $30 \mathrm{~min}$ (LI30) and $60 \mathrm{~min}$ (LI60) after the CT.

\section{Statistical analysis}

Data analyses were performed using JMP $® 10$ (SAS Institute Inc., Cary, NC, USA). All data are illustrated as the median and interquartile ranges (IQR). The numeric variables of laboratory data were analyzed by the Steel-Dwass test. For the ROTEM parameters, the Dunnett's multiple comparison tests were used to identify statistically significant differences vs. the control group. Correlations between the laboratory data and ROTEM parameters were investigated by Pearson's correlation coefficient test and linear regression analysis. $P$ values of $<0.05$ were considered to be statistically significant.
(A)
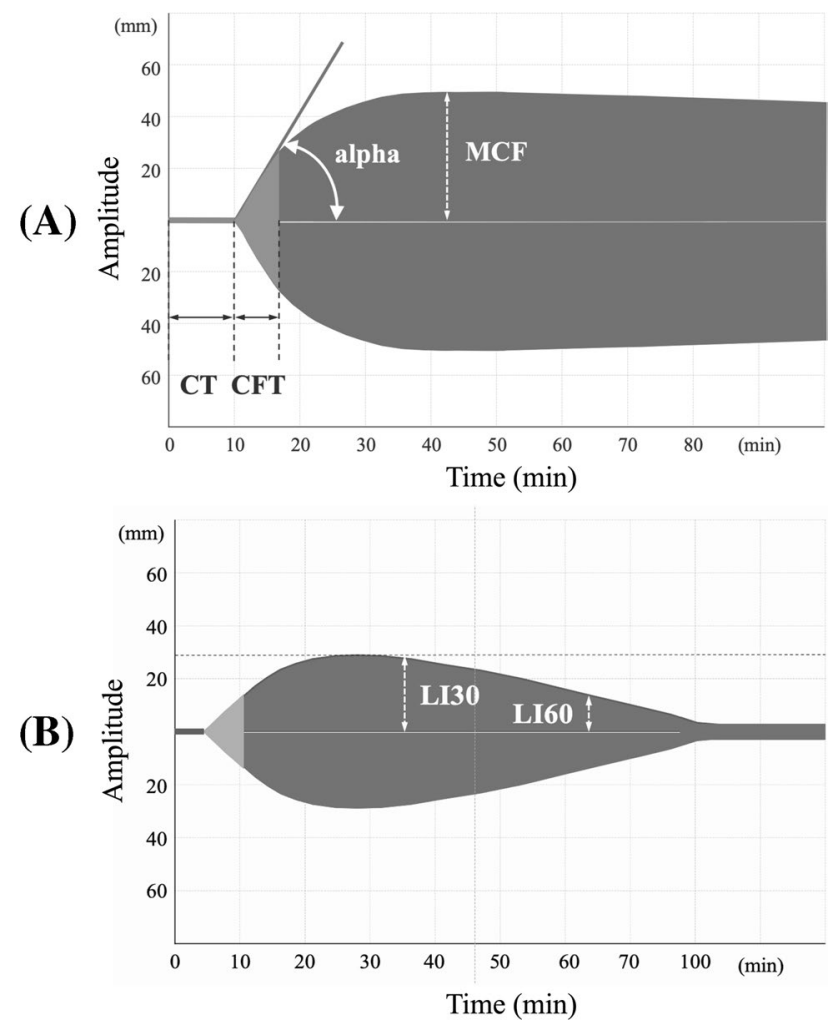

Fig. 1 Representative thromboelastograms together with coagulation and fibrinolysis parameters obtained by ROTEM. Panel (a) shows representative EXTEM data in a whole blood sample from a control individual. The coagulation parameters are as follows: CT, clotting time; CFT, clot formation time; MCF, maximum clot formation; alpha, $\alpha$-angle. Panel (b) shows corresponding representative FIBTEM data from a control subject. The fibrinolysis parameters are as follows: LI30, lysis index at $30 \mathrm{~min}$; LI60, lysis index at $60 \mathrm{~min}$

\section{Results}

\section{Patients' clinical characteristics}

Forty-four children with INS (30 boys: 14 girls) and 15 controls ( 6 boys: 9 girls) were enrolled. Of the 44 patients, 22 (13 boys: 9 girls) were identified in the initial group, and 22 (17 boys: 5 girls) in the relapse group. All patients were steroid-sensitive with no overt, clinically observed thrombotic events. The clinical characteristics of the enrolled patients are summarized in Table 1. The median age of initial group at admission was 5.1 years (IQR; 2.9-10.0 years). The median age of relapse group was 7.5 years (4.6-10.6 years). The median age of the control group was 5.0 years (1.0-8.0 years). The time to remission after CS therapy was 9.0 days in the initial group and 10.0 days in the relapse group.

Table 2 summarizes conventional laboratory data in the initial group (at $0 \mathrm{~W}$ ) just before CS therapy, the relapse group, and the control group. Measurements of $\mathrm{Hb}, \mathrm{Ht}$, and 
Table 1 Demographic and clinical characteristics in the pediatric INS patients enrolled

\begin{tabular}{|c|c|c|c|}
\hline & $\begin{array}{l}\text { Initial group } \\
n=22\end{array}$ & $\begin{array}{l}\text { Relapse group } \\
n=22\end{array}$ & $\begin{array}{l}\text { Control } \\
n=15\end{array}$ \\
\hline Age (yrs.) & $5.1[2.9-10.0]$ & $7.5[4.7-10.6]$ & $5.0[1.0-8.0]$ \\
\hline Sex; Male (\%) & $13(59)$ & $17(77)$ & $6(36)$ \\
\hline $\begin{array}{r}\text { Time to remission } \\
\text { after CST (days) }\end{array}$ & 9.0 [8.5-11.5] & $10.0[8.0-12.0]$ & - \\
\hline
\end{tabular}

Data are presented as the median (IQR)

CST corticosteroid therapy

$\mathrm{UP} / \mathrm{Cr}$ in both the initial and relapse groups were higher than in the control group $(p<0.05)$. Hb and $\mathrm{Ht}$ values were within reference range, however. Fibrinogen levels in the initial and relapse groups were higher than in controls $(p<0.05)$ and were higher in the initial group than in relapse $(p<0.05)$. TP, Alb, and AT assays in the initial group were lower than those in both the relapse and control groups $(p<0.05)$, and were lower in the relapse group compared to controls $(p<0.05)$. FDP and D-dimer values in the initial group were higher than in the relapse and control groups $(p<0.05)$. No significant differences between the groups were evident with the other parameters.

Table 3 summarizes the changes of laboratory characteristics in the initial group during follow-up. TP and Alb measurements were lowest at $0 \mathrm{~W}$ but recovered time-dependently close to the control range. Compared to the control group, the median of $\mathrm{Hb}$ and Plt remained high throughout the observation period. Fibrinogen levels were highest at $0 \mathrm{~W}$, decreased at $2 \mathrm{~W}$, and then gradually fell to below or near the lower limit of the normal range. AT levels were lower than controls at $0 \mathrm{~W}$ but were increased at $1 \mathrm{~W}$ and remained higher than controls thereafter. The UP/Cr ratios were high at $0 \mathrm{~W}$ and returned to the normal range at $2 \mathrm{~W}$ in most cases.

\section{Coagulation potential assessed by EXTEM in pediatric INS}

Comprehensive coagulation potential was assessed in pediatric INS patients using the EXTEM viscoelastic method. Representative thromboelastograms of EXTEM (Fig. 2A) in controls (panel a) and INS at $0 \mathrm{~W}$ (panel $\mathrm{b}$ ) demonstrate that the CT and CFT were shorter, and MCF and $\alpha$-angle were greater in the INS patients than in the controls.

These coagulation parameters (CT, CFT, MCF, and $\alpha$-angle) obtained by EXTEM in the initial INS group $(0-4 \mathrm{~W})$ and at relapse are illustrated in detail in Fig. 3 (panels a-d). In the initial group, CT and CFT at $0 \mathrm{~W}$ and $1 \mathrm{~W}$ were shorter than in controls $(p<0.01)$. Thereafter, both CT and CFT returned to within the normal range. In contrast, CFT at $3 \mathrm{~W}$ and $4 \mathrm{~W}$ appeared to be longer than in controls $(p<0.05)$. MCF and $\alpha$-angle at $0 \mathrm{~W}$ and $1 \mathrm{~W}$ were significantly greater than those in controls $(p<0.01)$, and both decreased to near normal limits after $2 \mathrm{~W}$. MCF, estimated
Table 2 Comparison of laboratory findings between the pediatric INS group and control group

\begin{tabular}{|c|c|c|c|c|c|c|c|}
\hline \multirow[b]{2}{*}{$\mathrm{Hb}(\mathrm{g} / \mathrm{dL})$} & \multicolumn{2}{|c|}{ Initial group } & \multicolumn{2}{|c|}{ Relapse group } & \multicolumn{2}{|c|}{ Control group } & \multirow{2}{*}{$\frac{P \text { value }}{* / \$}$} \\
\hline & 13.4 & $(12.9-14.1)$ & 13.4 & $(12.7-14.6)$ & 12.5 & $(12.0-13.6)$ & \\
\hline $\mathrm{Ht}(\%)$ & 40.3 & $(39.2-42.2)$ & 41.0 & $(38.6-44.0)$ & 37.4 & $(34.9-39.7)$ & $* / \$$ \\
\hline Plt $\left(\times 10^{4} / \mathrm{dL}\right)$ & 27.0 & $(30.6-40.3)$ & 30.8 & $(28.1-33.1)$ & 29.4 & $(27.2-34.6)$ & NS \\
\hline $\mathrm{T}-\mathrm{TP}(\mathrm{g} / \mathrm{dL})$ & 3.9 & $(3.6-4.3)$ & 5.6 & $(5.3-5.9)$ & 6.8 & $(6.6-7.1)$ & $* / \dagger / 申$ \\
\hline S-Alb (g/dL) & 1.8 & $(1.6-2.1)$ & 3.4 & $(3.1-3.6)$ & 4.5 & $(4.4-4.6)$ & $* / \dagger / \ddagger$ \\
\hline $\mathrm{UP} / \mathrm{Cr}(\mathrm{g} / \mathrm{gCr})$ & 13.4 & $(8.2-18.0)$ & 12.1 & $(3.3-14.9)$ & 0.02 & $(0.02-0.02)$ & $* / \$$ \\
\hline PT-INR & 0.99 & $(0.95-1.00)$ & 1.01 & $(0.99-1.04)$ & 1.04 & $(0.97-1.06)$ & NS \\
\hline APTT (sec) & 31.8 & $(27.9-34.7)$ & 29.9 & $(28.1-32.3)$ & 28.0 & $(26.1-30.4)$ & NS \\
\hline Fibrinogen $(\mathrm{mg} / \mathrm{dL})$ & 710 & $(561-801)$ & 395 & $(323-425)$ & 244 & $(227-273)$ & $* / \dagger / \$$ \\
\hline Antithrombin (\%) & 68.1 & $(57.5-82.5)$ & 93.6 & $(81.5-106)$ & 111 & $(110-113)$ & $* / \dagger / \ddagger$ \\
\hline $\mathrm{FDP}(\mu \mathrm{g} / \mathrm{mL})$ & 5.6 & $(3.4-6.1)$ & 2.7 & $(2.5-2.8)$ & 2.5 & $(2.5-2.5)$ & $* / \dagger$ \\
\hline D-dimer $(\mu \mathrm{g} / \mathrm{mL})$ & 2.1 & $(1.1-2.4)$ & 0.7 & $(0.6-0.8)$ & 0.59 & $(0.5-0.7)$ & $* / \dagger$ \\
\hline Plasminogen (\%) & 98.3 & $(81-106)$ & 97.1 & $(93-104)$ & - & & NS \\
\hline$\alpha 2 \mathrm{PI}(\%)$ & 101 & $(93-113)$ & 110 & $(100-122)$ & - & & \\
\hline TAT (ng/mL) & 2.8 & $(1.5-3.4)$ & 4.7 & $(1.4-3.6)$ & - & & NS \\
\hline $\mathrm{PIC}(\mu \mathrm{g} / \mathrm{mL})$ & 0.6 & $(0.3-0.9)$ & 0.3 & $(0.2-0.4)$ & - & & $\dagger$ \\
\hline Total PAI-1 (ng/mL) & 17.6 & $(10.0-22.3)$ & 19.0 & $(10.0-25.0)$ & - & & NS \\
\hline
\end{tabular}

Data are presented as the median (IQR)

*Initial group vs. control group; $\dagger$ Initial group vs. relapse group; $\ddagger$ Relapse group vs. control group

Statistical significance of differences among the three groups was calculated using Steel-Dwass test $P$ values of $<0.05$ were considered to be statistically significant 
Table 3 Change of laboratory data during the follow-up period in the initial group

\begin{tabular}{lcccccc}
\hline & \multicolumn{2}{l}{ Initial group } & & & & Control \\
\cline { 2 - 6 } & $0 \mathrm{~W}$ & $1 \mathrm{~W}$ & $2 \mathrm{~W}$ & $3 \mathrm{~W}$ & $4 \mathrm{~W}$ & \\
\hline $\mathrm{TP}(\mathrm{g} / \mathrm{dL})$ & $3.9(3.6-4.5)$ & $4.5(4.1-5.0)$ & $5.6(5.3-6.1)$ & $6.0(5.6-6.2)$ & $6.1(5.6-6.5)$ & $6.8(6.6-7.1)$ \\
$\mathrm{Alb}(\mathrm{g} / \mathrm{dL})$ & $1.8(1.6-2.1)$ & $2.4(2.2-2.7)$ & $3.3(3.1-3.5)$ & $3.7(3.6-3.9)$ & $4.1(3.7-4.2)$ & $4.5(4.4-4.6)$ \\
$\mathrm{Hb}(\mathrm{g} / \mathrm{dL})$ & $13.4(12.9-14.1)$ & $13.6(13.0-14.2)$ & $13.6(13.2-14.5)$ & $13.5(13.2-14.3)$ & $13.5(12.7-14.2)$ & $12.5(12.0-13.6)$ \\
$\mathrm{Plt}\left(\mathrm{X} 10^{4} / \mu \mathrm{L}\right)$ & $35.7(29.6-40.3)$ & $47.4(38.2-54.9)$ & $45.2(41.7-60.9)$ & $35.7(29.4-47.6)$ & $32.1(28.9-38.6)$ & $29.4(27.2-34.6)$ \\
Fibrinogen $(\mathrm{mg} / \mathrm{dL})$ & $624(574-736)$ & $355(327-426)$ & $208(167-280)$ & $160(142-191)$ & $168(147-227)$ & $244(227-273)$ \\
Antithrombin $(\%)$ & $68(58-84)$ & $135(90-140)$ & $150(140-150)$ & $150(147-150)$ & $150(140-150)$ & $111(110-113)$ \\
$\mathrm{UP} / \mathrm{Cr}(\mathrm{g} / \mathrm{gCre})$ & $12.6(8.5-17.9)$ & $0.91(0.20-11.5)$ & $0.12(0.09-0.21)$ & $0.11(0.06-0.14)$ & $0.10(0.06-0.13)$ & $0.02(0.02-0.02)$ \\
\hline
\end{tabular}

Data are presented as the median (IQR)

$0 \mathrm{~W}, 1 \mathrm{~W}, 2 \mathrm{~W}, 3 \mathrm{~W}, 4 \mathrm{~W}$; whole blood samples at 1,2,3, and 4 weeks after the CS therapy, respectively

Fig. 2 Representative EXTEM and FIBTEM thromboelastograms in a control individual and a pediatric INS patient. A EXTEM: TF $(0.5 \mathrm{pM})$ and $\mathrm{CaCl}_{2}$ were added to citrated whole blood sample for the EXTEM assay. Panel (a) shows a representative EXTEM pattern in whole blood from a control individual. Panel (b) shows a representative EXTEM pattern in whole blood from a pediatric INS patient. B FIBTEM: TF $(0.5 \mathrm{pM}), \mathrm{CaCl}_{2}$, and tPA $(2 \mathrm{nM})$ were added to citrated whole blood sample for the FIBTEM assay. Panel (a) shows a representative FIBTEM pattern in whole blood from a control individual. Panel (b) shows a representative FIBTEM pattern in whole blood from a pediatric INS patient
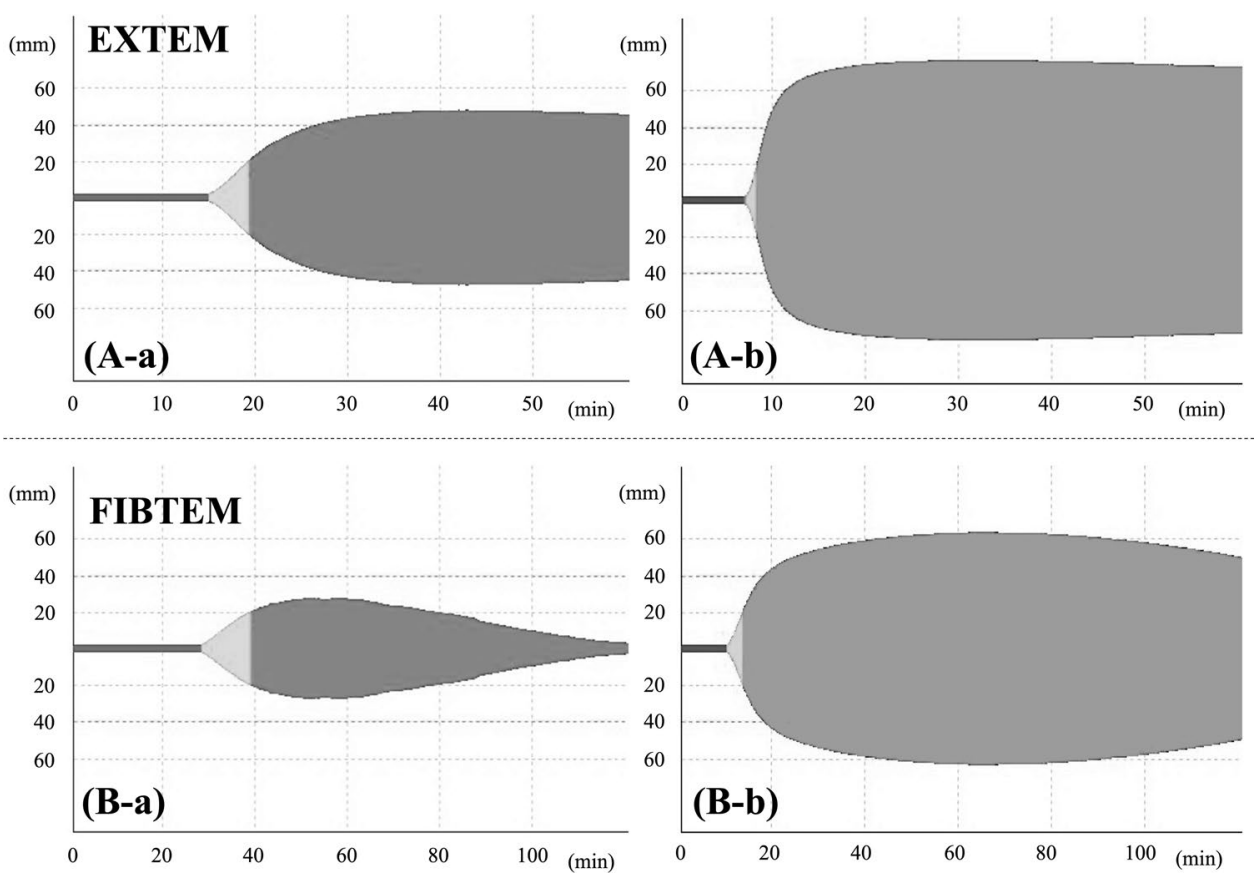

at $3 \mathrm{~W}$ and $4 \mathrm{~W}$, were lower than in controls ( $p<0.01)$, however. In the relapsed patients, CT was significantly shorter than that in controls $(p<0.01)$, and although the CFT appeared to be low in the INS group, the differences were not statistically significant. Both MCF and $\alpha$-angle were greater in the relapsed group than in controls $(p<0.01)$.

Overall, these EXTEM parameters at the initial onset of INS (within $1 \mathrm{~W}$ ) and at relapse were consistent with a likely hypercoagulable state.

\section{Fibrinolytic potential determined by FIBTEM in pediatric INS patients}

The principles of ROTEM were also extended to examine global fibrinolytic potential (FIBTEM) in pediatric INS. As above, representative thromboelastograms obtained by FIBTEM (Fig. 2B) in the controls (panel a) and the INS patients at $0 \mathrm{~W}$ (panel $\mathrm{b}$ ) illustrate that the fibrinolytic parameters were greater in the INS patients than in controls.

These fibrinolytic parameters (LI30 and LI60) obtained by FIBTEM in the initial INS patients (0-4 W) and at relapse are highlighted in Fig. 3 (panels e-f). In the initial group, LI30 and LI60 at 0-4 W were markedly greater than in controls $(p<0.01)$. In the relapse group, LI30 was significantly greater than in controls $(p<0.05)$, but, although the LI60 in the relapsed patients tended to be greater than in controls, the differences were not statistically significant $(p=0.06)$. These results were in keeping with the concept that fibrinolysis was more defective at the initial onset of pediatric INS $(0-4 \mathrm{~W})$ than at relapse. 
(a) $\mathrm{CT}$

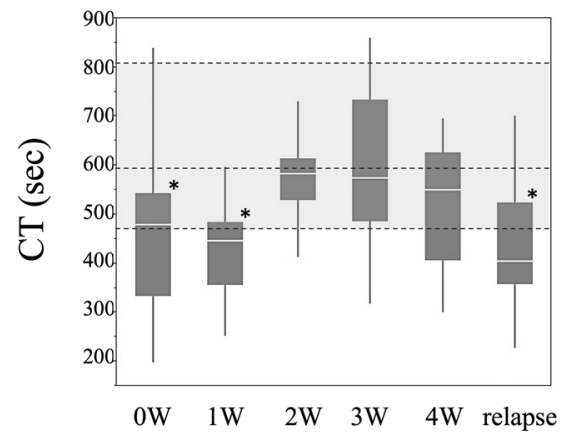

(d) Alpha

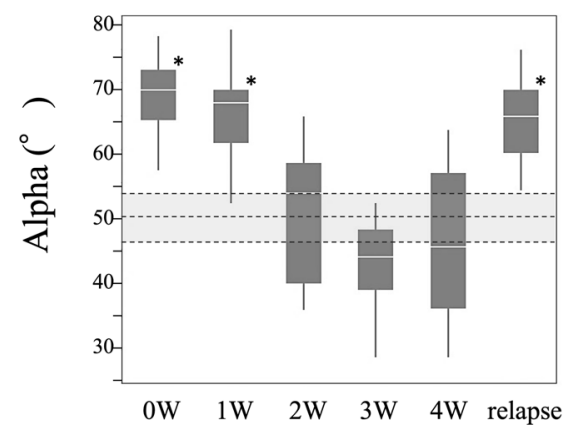

(b) CFT

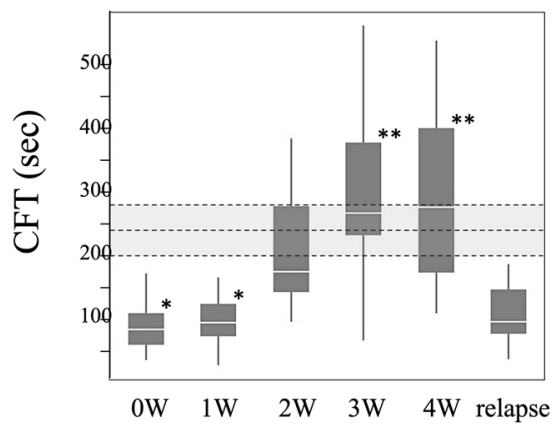

(e) LI30

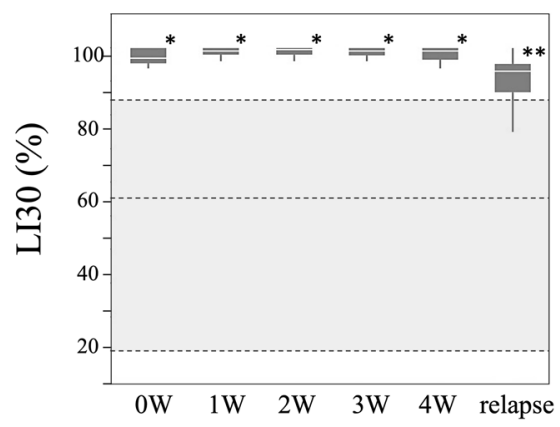

(c) $\mathrm{MCF}$

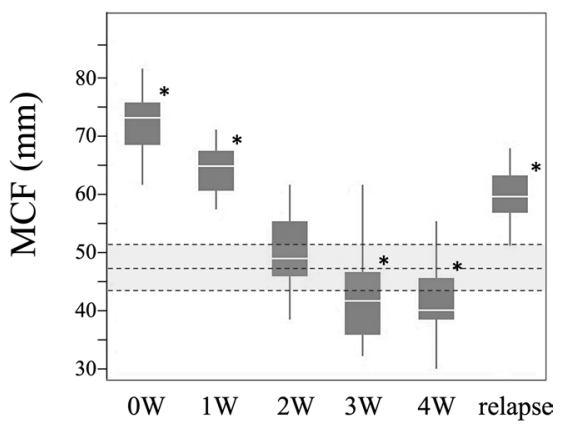

(f) LI60

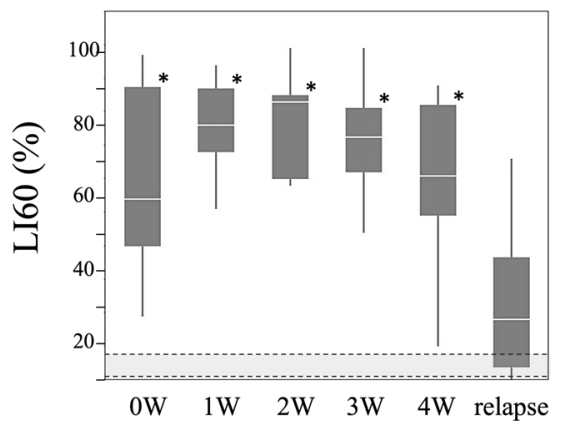

Fig. 3 Changes in EXTEM and FIBTEM parameters over time in pediatric INS patients. TF $(0.5 \mathrm{pM})$ and $\mathrm{CaCl}_{2}$ were added to citrated whole blood, followed by EXTEM analysis, and TF (0.5 pM), $\mathrm{CaCl}_{2}$, and tPA $(2 \mathrm{nM})$ were added to citrated whole blood, followed by the FIBTEM analysis as described in Methods. The EXTEM parameters (a CT, b CFT, $\mathbf{c}$ MCF, and $\mathbf{d} \alpha$-angle) and the FIBTEM parameters (e LI30 and f LI60) in the initial group at 0-4 weeks after corticosteroid

\section{Relationship between EXTEM/FIBTEM parameters and conventional laboratory assays}

The results of these analyses of global hemostasis were further assessed to examine the relationship between the ROTEM parameters and conventional laboratory tests. The effects of CS therapy on coagulation mechanisms could have influenced the data, however, and comparisons were limited, therefore, using samples at $0-1 \mathrm{~W}$ in the initial group. The EXTEM parameters (Fig. 4A), demonstrated that both the MCF and $\alpha$-angle correlated with Alb and fibrinogen $(r=0.70, p<0.001 ; r=0.68, p<0.001$; and $r=0.50, p<0.007 ; r=0.50, p=0.001$, respectively). The FIBTEM parameters (Fig. 4B), suggested that LI60 correlated weakly with $\mathrm{IgG}$ and fibrinogen $(r=0.43, p=0.021$; $r=0.45, p=0.004$, respectively), but no significant correlations were evident between the L130 or L160 parameters and the specific fibrinolysis markers, D-dimer, PIC, and $\alpha 2$-PI (L130, $p=0.67,0.74$, and 0.05 , respectively and LI60, $p=0.36,0.07$, and 0.37 , respectively; data not shown). therapy and in the relapse group are shown. Each box plot represents the interquartile range with mean values (horizontal line). The gray zone shows the range of EXTEM and FIBTEM parameters in control individuals $(n=15)$. Significant differences between control individuals and relapse group or initial group were considered $p<0.05$. ${ }^{*} p<0.01,{ }^{* *}<0.05$

\section{Discussion}

VTE is a rare but life-threatening complication of INS in childhood. For example, some findings indicated that the incidence of VTE in adults ranged from 20-50\% whereas the rate was approximately $3 \%$ in pediatric patients [1]. A later report demonstrated, however, that VTE could be detected in pediatric patients by radiographic technology even in the absence of clinical findings [9]. The pathogenesis of thrombosis appears likely to involve a combination of multiple mechanisms including those involved in coagulation and fibrinolysis, platelet function, vascular endothelial disturbances, and blood viscosity. Furthermore, a wide range of underlying diseases are known to contribute to thrombotic complications, and critical disturbances in hemostasis may vary depending on the underlying disease. In this context, the clarification of thrombotic mechanism(s) is especially needed to establish prophylactic antithrombotic therapy in pediatric INS patients. Plasma-based measurements, such as PT, APTT, and fibrinogen, are generally used to evaluate blood coagulation, but these in vitro tests provide only 
Fig. 4 Correlation between laboratory data and coagulation and fibrinolysis parameters obtained by ROTEM in pediatric INS patients. The ROTEM parameters obtained in whole blood samples from the initial group at $0-1 \mathrm{~W}$ and shown in Fig. 3 were analyzed as follows. A EXTEM parameters $(\alpha$ and MCF) are presented on the $y$-axis. Serum Alb, fibrinogen, and AT values are presented on the $x$-axis. B FIBTEM parameter (LI60) is presented on the $y$-axis. Fibrinogen and IgG values are presented on the $x$-axis. The correlation coefficients $(r)$ are shown (straight line). Significant differences between laboratory data and ROTEM parameters was shown as $p<0.05$

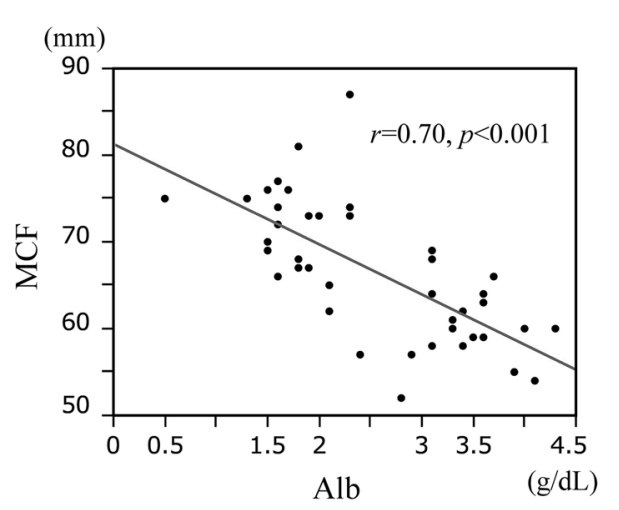

(A)
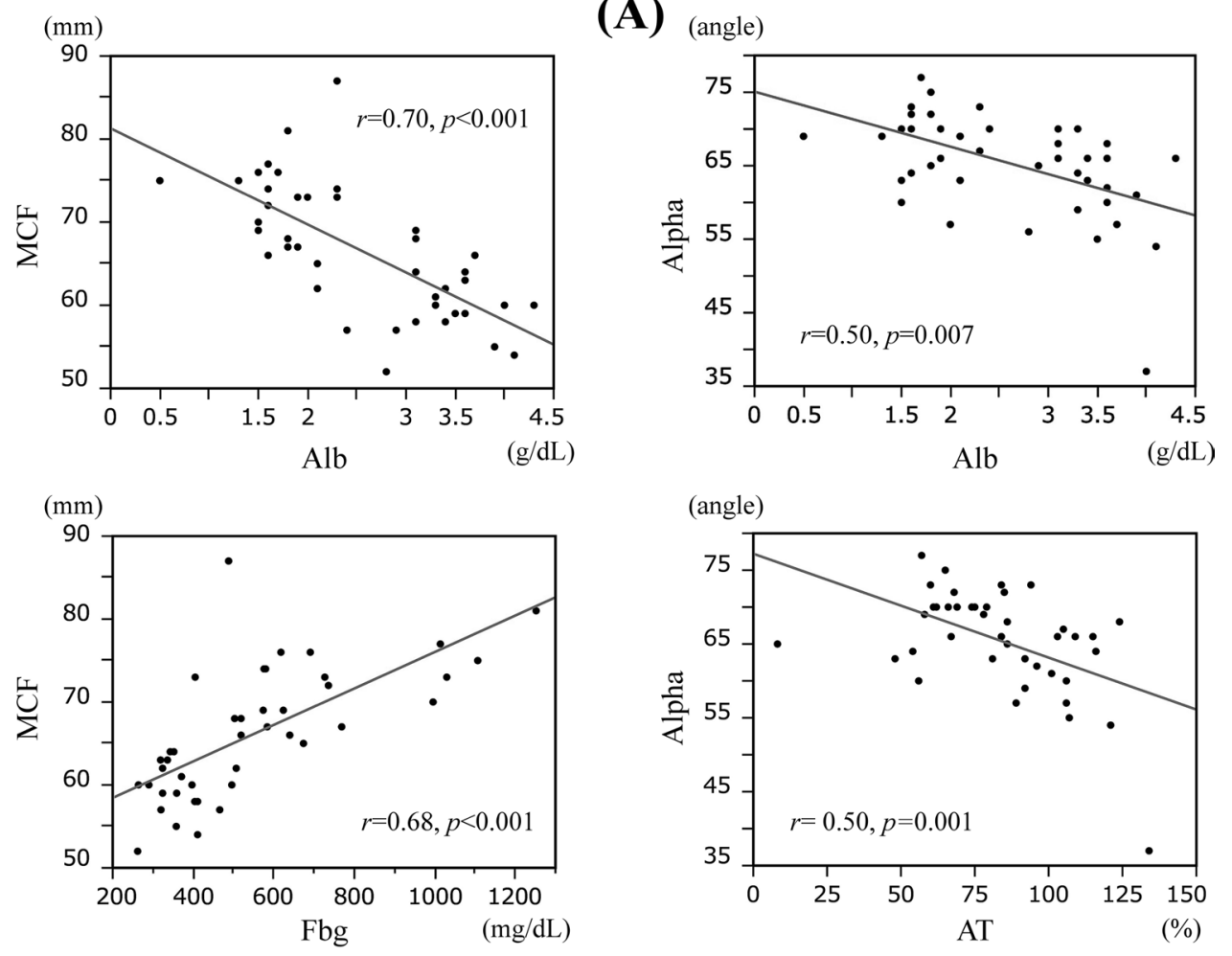

(B)

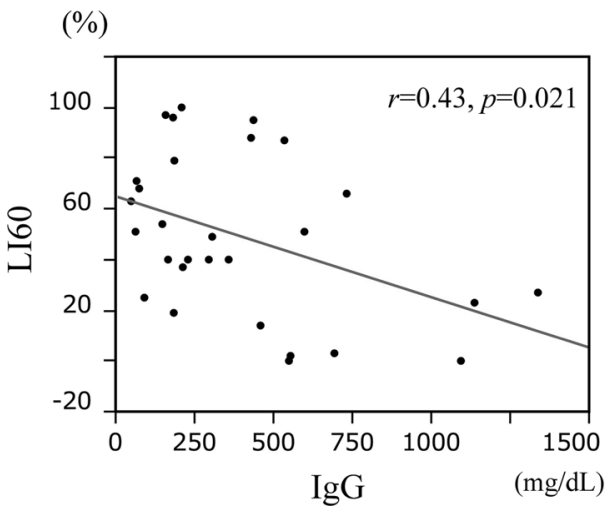

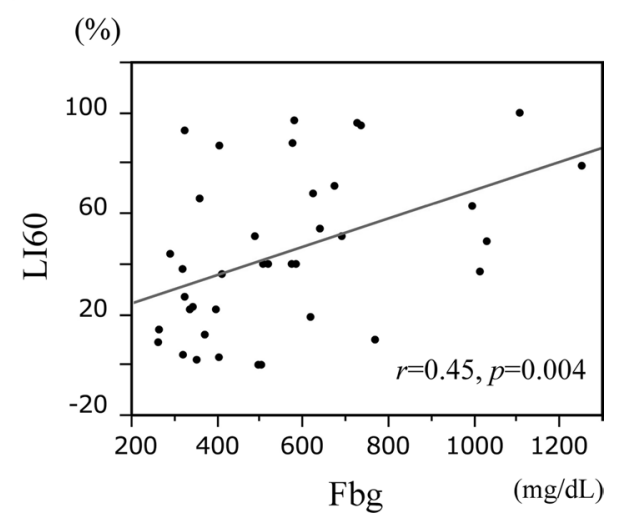

limited information about in vivo, physiological processes. Global coagulation assays such as TEG, ROTEM, and thrombin generation [29], therefore, have focused on whole blood techniques to assess the complex role of interacting mechanisms governing hemostasis, including platelets and other blood cell components.

Consequently, thromboelastography (TEG) was devised as a rheological assay to estimate overall coagulation and fibrinolytic potential in whole blood, and assessments in various clinical situations, including trauma and postoperative management, have confirmed the effectiveness of the technique for evaluating disordered coagulation pathology $[17,18]$. TEG has been recently reported to be informative for assessing comprehensive coagulability in adult patients with different pathological types of NS [26]. Moreover, Huang et al. [30, 31] reported that patients with membranous nephropathy tend to be more hypercoagulable than normal individuals and patients with MCD. ROTEM is a more recent modification of TEG that provides a visual assessment of clot formation and subsequent lysis under low shear, similar to those present under venous flow conditions [15-18, 22]. In particular, ROTEM parameters appeared to correlate better with fibrinogen concentration and hyperfibrinolysis relative to TEG [32]. Moreover, Kerlin et al. [25] used ROTEM in a puromycin aminonucleosideinduced rat nephrosis model to demonstrate that proteinuria and hypoalbuminemia could be clinically meaningful surrogate biomarkers of hypercoagulopathy. In the present 
study, therefore, ROTEM was adapted to assess the overall coagulation and fibrinolytic potential in pediatric INS patients, and the results indicate that a hypercoagulable state and decreased fibrinolytic activity co-exist in the acute phase of this syndrome. In addition, dynamic changes in blood coagulation were observed within 4 weeks post-initiation of the CS therapy.

Regarding conventional laboratory data, AT and fibrinogen levels showed biphasic trends, normalizing once and then shifting ro the opposite side of the reference value after CS treatment. TP and Alb levels, which affect blood viscosity, gradually normalized over time, while $\mathrm{Hb}$ and Plt counts remained higher than those in the control group throughout the observation period, but the phenomenon appeared unlikely to be clinically meaningful. FDP and D-dimer levels were elevated, while TAT and PIC levels were not significantly elevated compared to the control group. Whereas, Kerlin et al. reported that in the PAN-induced rat nephrosis model, TAT and D-dimer levels were not significantly elevated and the hemostatic system remained quiescent in vivo in the absence of insults that would activate the hemostatic mechanism [25]. The insults that cause thrombosis include trauma, obesity, cardiovascular disease, venous catheter-related endothelial injury, or venous stasis related to edema, poor perfusion, bed rest, and so on. The precise mechanism(s) for the FDP and D-dimer being elevated while the TAT and PIC were not, is unclear. One possibility, however, may be the influence of the presence of ascites or pleural effusion. Agarwal et al. [33] suggested the possibility of ascites as a cause of high D-dimer levels in blood and ascites in cirrhotic patients. The elevated blood levels of FDP and D-dimer formed in ascites and pleural effusion may be due to their migration into the circulating blood, but may not be the state of systemic coagulation activation as reported by Kerlin et al. [25]. With such complicated changes of many factors in the laboratory data, it was difficult to accurately assess the changes in blood coagulation.

The EXTEM test of ROTEM reflects extrinsic coagulation, and our investigations using this method revealed a hypercoagulable state both in the initial INS group at $0-1 \mathrm{~W}$ and in the relapse group. In the initial group, the coagulation potential returned to normal at $2 \mathrm{~W}$, but the CFT was prolonged and the MCF was decreased at 3-4 W compared to controls. These findings suggested delayed thrombus formation and weak clot firmness during these times. Waller et al. [34] analyzed blood samples from patients with childhood NS using thrombin generation and have reported that CS treatment reduced NS-related thrombotic risk in children. Importantly, the experiments demonstrated for the first time that the pathophysiology of hypercoagulability in the initial group was significantly changed during CS therapy using ROTEM. Comparisons of the ROTEM parameters with conventional laboratory assays identified a strong negative correlation between MCF with Alb levels and a strong positive correlation with fibrinogen concentrations. In addition, $\alpha$-angle showed negative correlations with Alb and AT levels. In particular, our results illustrated that fibrinogen and Alb levels correlated well with ROTEM parameters. These data were in keeping with earlier reports demonstrating that hypoalbuminemia, hyperfibrinogenemia, and low AT levels were risk factors for VTE in NS [3, 4, 14, 35], and that fibrinogen and Alb could be useful markers of the overall coagulability in pediatric INS patients.

The FIBTEM technique was originally devised to study fibrinolysis potential. In the present study, we utilized the additional reagent of tPA to evaluate clot stability for hyperfibrinolytic conditions. Several groups have modified ROTEM to induce fibrinolysis such that it would become more sensitive to changes in the fibrinolytic system [36, 37]. This method is artificial for assessment of fibrinolysis, however. The current data suggested a predominant decrease in fibrinolytic activity both in the initial group at 0-4 W and in the relapse group. Lisman et al. [38, 39] reported the involvement of hypercoagulability and hypofibrinolysis in the thrombotic pathogenesis, for example, in COVID-19 and acute-on-chronic liver failure. In NS patients, fibrinolytic activity is known to decrease in association with hypercoagulability [3, 40], but in our initial group the parameters of fibrinolytic activity at 2-4 W were decreased despite the absence of hypercoagulability. Hence, unlike earlier reports, the coagulability and fibrinolytic activity appeared to vary independently. In addition, the LI60 parameter correlated weakly with IgG and fibrinogen levels, but there were no significant correlations between the FIBTEM parameters and standard markers of fibrinolysis including D-dimer, PIC, and $\alpha 2$ PI. The findings indicated, therefore, that conventional fibrinolytic measurements appeared unlikely to adequately reflect fibrinolytic activity in pediatric INS patients.

The new observation from the present study was that CS therapy did not correct the hypofibrinolytic state at least by 4 weeks after treatment. One reason may be the effect of CS therapy-mediated PAI-1 induction on fibrinolytic activity. Sartori et al. [35] reported that fibrinolytic activity was significantly decreased in kidney transplant recipients treated with CS, suggesting the likely significant influence of CS on fibrinolytic function. Similarly, other reports have demonstrated that CS increased levels of PAI-1, leading to decreased fibrinolytic activity [41-43]. In the present study, since PAI-1 was not measured during CS therapy, its involvement is unclear. Another reason may be related to the synthetic rates of various components on fibrinolytic system, and the etiology remains an open question.

There are some limitations with the present study. Firstly, the number of patients involved was relatively low, and no VTE events were observed. Secondly, the principles of the ROTEM technique do not take account of the role of 
physiological blood flow or the localized effects of disturbed vascular endothelial cells. In recent years, automated systems for analyzing whole blood coagulation under variable shear-flow have been developed [44-46], and these have been applied clinically to assess total thrombus formation. Studies utilizing this technology are under development in our laboratory. Finally, positive controls were not available for the present study, although ROTEM has been adopted to evaluate hypercoagulability in Cushing's syndrome and in severe COVID-19 pneumonia [47, 48]. Experiments of this nature have not been fully standardized, however, and the influence of other pathophysiologies on ROTEM data remains to be thoroughly compared. Consequently, prophylactic antithrombotic protocols to prevent the onset of VTE in pediatric INS patients are controversial. Nevertheless, our current results were consistent with an important role for hypercoagulable and hypofibrinolytic mechanisms possibly associated with an increased risk of VTE in the acute phase of INS. Our findings could help to provide appropriate predictive treatment for VTE in INS.

Author contribution TI designed the research, assessed the patients clinically, performed the experiments, analyzed the data, prepared the figures, and wrote the paper; YN interpreted the data, and wrote the paper; TO performed the experiments, and assessed the patients clinically; KO interpreted the data, and supervised the study; KN designed the research, interpreted the data, prepared the figures, wrote the paper, edited the manuscript, and approved the final version to be published.

Funding This work was partly supported by a Grant-in-Aid for Scientific Research (KAKENHI) from the Ministry of Education, Culture, Sports, Science and Technology (MEXT) to KN (18K07885).

Data availability The datasets generated during and/or analyzed during the current study are available from the corresponding author on reasonable request.

\section{Declarations}

Conflict of interest The authors declare no competing interests.

\section{References}

1. Kerlin BA, Ayoob R, Smoyer WE (2012) Epidemiology and pathophysiology of nephrotic syndrome-associated thromboembolic disease. Clin J Am Soc Nephrol 7:513-520. https://doi.org/ 10.2215/CJN.10131011

2. Kerlin BA, Haworth K, Smoyer WE (2014) Venous thromboembolism in pediatric nephrotic syndrome. Pediatr Nephrol 29:989997. https://doi.org/10.1007/s00467-013-2525-5

3. Citak A, Emre S, Sairin A, Bilge I, Nayir A (2000) Hemostatic problems and thromboembolic complications in nephrotic children. Pediatr Nephrol 14:138-142. https://doi.org/10.1007/s0046 70050029

4. Mehls O, Andrassy K, Koderisch J, Herzog U, Ritz E (1987) Hemostasis and thromboembolism in children with nephrotic syndrome: differences from adults. J Pediatr 110:862-867. https:// doi.org/10.1016/s0022-3476(87)80397-9

5. Ueda N, Kawaguchi S, Niinomi Y, Nonoda T, Matsumoto J et al (1987) Effect of corticosteroids on coagulation factors in children with nephrotic syndrome. Pediatric Nephrol 1:286-289. https:// doi.org/10.1007/BF00849225

6. Lilova MI, Velkovski IG, Topalov IB (2000) Thromboembolic complications in children with nephrotic syndrome in Bulgaria (1974-1996). Pediatric Nephrol 15:74-78. https://doi.org/10. $1007 / \mathrm{s} 004679900253$

7. Kerlin BA (2009) Epidemiology and risk factors for thromboembolic complications of childhood nephrotic syndrome-a Midwest Pediatric Nephrology Consortium (MWPNC) study. J Pediatr 155:105-110. https://doi.org/10.1016/j.jpeds.2009.01.070

8. Setty BA, O'Brien SH, Kerlin BA (2012) Pediatric venous thromboembolism in the United States: a tertiary care complication of chronic diseases. Pediatr Blood Cancer 59:258-264. https://doi. org/10.1002/pbc.23388

9. Zhang LJ, Wang ZJ, Zhou CS, Lu L, Luo S et al (2012) Evaluation of pulmonary embolism in pediatric patients with nephrotic syndrome with dual energy CT pulmonary angiography. Acad Radiol 19:341-348. https://doi.org/10.1016/j.acra.2011.11.002

10. Mittal A, Aggarwal KC, Saluja S, Aggarwal A, Sureka B (2013) Platelet functions and coagulation changes in Indian children with nephrotic syndrome. J Clin Diagn Res 7:1647-1650. https://doi. org/10.7860/JCDR/2013/5488.3229

11. Suri D, Ahluwalia J, Saxena AK, Sodhi KS, Singh P et al (2014) Thromboembolic complications in childhood nephrotic syndrome: a clinical profile. Clin Exp Nephrol 18:803-813. https://doi.org/ 10.1007/s10157-013-0917-2

12. Hamasaki Y, Hamada R, Muramatsu M, Matsumoto S, Aya K et al (2020) A cross-sectional nationwide survey of congenital and infantile nephrotic syndrome in Japan. BMC Nephrol 21:363. https://doi.org/10.1186/s12882-020-02010-5

13. Tkaczyk M, Baj Z (2002) Surface markers of platelet function in idiopathic nephrotic syndrome in children. Pediatr Nephrol 17:673-677. https://doi.org/10.1007/s00467-002-0865-7

14. Zaffanello M, Franchini M (2007) Thromboembolism in childhood nephrotic syndrome: a rare but serious complication. Hematology 12:69-73. https://doi.org/10.1080/10245330600940048

15. Whiting D, DiNardo JA (2014) TEG and ROTEM: technology and clinical applications. Am J Hematol 89:228-232. https://doi. org/10.1002/ajh.23599

16. Crochemore T, Piza FMT, Rodrigues RDR, Guerra JCC, Ferraz LJR et al (2017) A new era of thromboelastometry. Einstein (Sao Paulo) 15:380-385. https://doi.org/10.1590/S1679-45082017MD 3130

17. Nogami K (2016) The utility of thromboelastography in inherited and acquired bleeding disorders. Br J Haematol 174:503-514. https://doi.org/10.1111/bjh.14148

18. Longstaff $\mathrm{C}$ (2018) Measuring fibrinolysis: from research to routine diagnostic assays. J Thromb Haemost 16:652-662. https:// doi.org/10.1111/jth.13957

19. McNamara H, Kenyon C, Smith R, Mallaiah S, Barclay P (2019) Four years' experience of a ROTEM $((\mathrm{R}))$-guided algorithm for treatment of coagulopathy in obstetric haemorrhage. Anaesthesia 74:984-991. https://doi.org/10.1111/anae.14628

20. Tomescu D, Popescu M, Dima SO (2018) Rotational thromboelastometry (ROTEM) 24 hours post liver transplantation predicts early allograft dysfunction. Rom J Anaesth Intensive Care 25:117-122. https://doi.org/10.21454/rjaic.7518.252.tms

21. Hunt H, Stanworth S, Curry N, Woolley T, Cooper C et al (2015) Thromboelastography (TEG) and rotational thromboelastometry (ROTEM) for trauma induced coagulopathy in adult trauma patients with bleeding. Cochrane Database Syst Rev:CD010438. https://doi.org/10.1002/14651858.CD010438.pub2 
22. Luz LTD, Nascimento B, Shankarakutty AK, Rizoli S, Adhikari NKJ (2014) Effect of thromboelastography (TEG®) and rotational thromboelastometry (ROTEM ${ }^{\circledR}$ ) on diagnosis of coagulopathy, transfusion guidance and mortality in trauma-descriptive systematic review. Crit Care 18:518. https://doi.org/10.1186/ s13054-014-0518-9

23. Wang X, Shi A, Huang J, Chen Y, Xue W et al (2020) Assessment of hypercoagulability using thromboelastography predicts advanced status in renal cell carcinoma. J Clin Lab Anal 34:e23017. https://doi.org/10.1002/jcla.23017

24. Donahue SM, Brooks M, Otto CM (2011) Examination of hemostatic parameters to detect hypercoagulability in dogs with severe protein-losing nephropathy. J Vet Emerg Crit Care (San Antonio) 21:346-355. https://doi.org/10.1111/j.1476-4431.2011.00656.x

25. Kerlin BA, Waller AP, Sharma R, Chanley MA, Nieman MT et al (2015) Disease severity correlates with thrombotic capacity in experimental nephrotic syndrome. J Am Soc Nephrol 26:30093019. https://doi.org/10.1681/ASN.2014111097

26. Lu C, Zuo K, Le W, Chen W, Qin W et al (2020) Characterization of thromboelastography of patients with different pathological types of nephrotic syndrome. Medicine (Baltimore) 99:e18960. https://doi.org/10.1097/MD.0000000000018960

27. (1982) International Study of Kidney Disease in Children: early identification of frequent relapsers among children with minimal change nephrotic syndrome. A report of the International Study of Kidney Disease in Children. J Pediatr 101:514-518. https://doi. org/10.1016/s0022-3476(82)80692-6

28. Trautmann A, Vivarelli M, Samuel S, Gipson D, Sinha A et al (2020) IPNA clinical practice recommendations for the diagnosis and management of children with steroid-resistant nephrotic syndrome. Pediatr Nephrol 35:1529-1561. https://doi.org/10.1007/ s00467-020-04519-1

29. Al Dieri R, de Laat B, Hemker HC (2012) Thrombin generation: what have we learned? Blood Rev 26:197-203. https://doi.org/10. 1016/j.blre.2012.06.001

30. Huang MJ, Wei RB, Li QP, Yang X, Cao CM et al (2016) Hypercoagulable state evaluated by thromboelastography in patients with idiopathic membranous nephropathy. J Thromb Thrombolysis 41:321-327. https://doi.org/10.1007/s11239-015-1247-x

31. Huang MJ, Wei RB, Wang ZC, Xing Y, Gao WY et al (2015) Mechanisms of hypercoagulability in nephrotic syndrome associated with membranous nephropathy as assessed by thromboelastography. Thromb Res 136:663-668. https://doi.org/10.1016/j. thromres.2015.06.031

32. Abuelkasem E, Lu S, Tanaka K, Planinsic R, Sakai T (2016) Comparison between thrombelastography and thromboelastometry in hyperfibrinolysis detection during adult liver transplantation. $\mathrm{Br}$ J Anaesth 116:507-512. https://doi.org/10.1093/bja/aew023

33. Agarwal S, Joyner KA Jr, Swaim MW (2000) Ascites fluid as a possible origin for hyperfibrinolysis in advanced liver disease. Am J Gastroenterol 95:3218-3224. https://doi.org/10.1111/j. 1572-0241.2000.03299.x

34. Waller AP, Agrawal S, Wolfgang KJ, Kino J, Chanley MA et al (2020) Nephrotic syndrome-associated hypercoagulopathy is alleviated by both pioglitazone and glucocorticoid which target two different nuclear receptors. Physiol Rep 8:e14515. https://doi.org/ $10.14814 /$ phy 2.14515

35. Glassock RJ (2007) Prophylactic anticoagulation in nephrotic syndrome: a clinical conundrum. J Am Soc Nephrol 18:2221-2225. https://doi.org/10.1681/ASN.2006111300

36. Kuiper GJ, Kleinegris MC, van Oerle R, Spronk HM, Lance MD et al (2016) Validation of a modified thromboelastometry approach to detect changes in fibrinolytic activity. Thromb J 14:1. https://doi.org/10.1186/s12959-016-0076-2
37. Hulshof AM, Bruggemann RAG, Mulder MMG, van de Berg TW, Sels JEM et al (2021) Serial EXTEM, FIBTEM, and tPA rotational thromboelastometry observations in the maastricht intensive care COVID cohort-persistence of hypercoagulability and hypofibrinolysis despite anticoagulation. Front Cardiovasc Med 8:654174. https://doi.org/10.3389/fcvm.2021.654174

38. Blasi A, von Meijenfeldt FA, Adelmeijer J, Calvo A, Ibanez C et al (2020) In vitro hypercoagulability and ongoing in vivo activation of coagulation and fibrinolysis in COVID-19 patients on anticoagulation. J Thromb Haemost 18:2646-2653. https://doi.org/10. 1111/jth. 15043

39. Meltzer ME, Lisman T, Doggen CJ, de Groot PG, Rosendaal FR (2008) Synergistic effects of hypofibrinolysis and genetic and acquired risk factors on the risk of a first venous thrombosis. PLoS Med 5:e97. https://doi.org/10.1371/journal.pmed.0050097

40. Colle JP, Mishal Z, Lesty C, Mirshahi M, Peyne J et al (1999) Abnormal fibrin clot architecture in nephrotic patients is related to hypofibrinolysis: influence of plasma biochemical modifications: a possible mechanism for the high thrombotic tendency? Thromb Haemost 82:1482-1489

41. Hozumi A, Osaki M, Sakamoto K, Goto H, Fukushima T et al (2010) Dexamethasone-induced plasminogen activator inhibitor-1 expression in human primary bone marrow adipocytes. Biomed Res 31:281-286. https://doi.org/10.2220/biomedres.31.281

42. Yamamoto Y, Ishizu A, Ikeda H, Otsuka N, Yoshiki T (2004) Dexamethasone increased plasminogen activator inhibitor-1 expression on human umbilical vein endothelial cells: an additive effect to tumor necrosis factor-alpha. Pathobiology 71:295-301. https:// doi.org/10.1159/000081724

43. Zonneveld AJV, Curriden SA, Loskutoff DJ (1988) Type 1 plasminogen activator inhibitor gene-functional analysis and glucocorticoid regulation of its promoter. Proc Natl Acad Sci U S A 85:5525-5529. https://doi.org/10.1073/pnas.85.15.5525

44. Hosokawa K, Ohnishi T, Fukasawa M, Kondo T, Sameshima H et al (2012) A microchip flow-chamber system for quantitative assessment of the platelet thrombus formation process. Microvasc Res 83:154-161. https://doi.org/10.1016/j.mvr.2011.11.007

45. Hosokawa K, Ohnishi T, Kondo T, Fukasawa M, Koide T et al (2011) A novel automated microchip flow-chamber system to quantitatively evaluate thrombus formation and antithrombotic agents under blood flow conditions. J Thromb Haemost 9:2029_ 2037. https://doi.org/10.1111/j.1538-7836.2011.04464.x

46. Sueta D, Kaikita K, Okamoto N, Arima Y, Ishii M et al (2015) A novel quantitative assessment of whole blood thrombogenicity in patients treated with a non-vitamin $\mathrm{K}$ oral anticoagulant. Int J Cardiol 197:98-100. https://doi.org/10.1016/j.ijcard.2015.06.041

47. Coelho MC, Vieira Neto L, Kasuki L, Wildemberg LE, Santos CV et al (2014) Rotation thromboelastometry and the hypercoagulable state in Cushing's syndrome. Clin Endocrinol (Oxf) 81:657-664. https://doi.org/10.1111/cen.12491

48. Pavoni V, Gianesello L, Pazzi M, Stera C, Meconi T et al (2020) Evaluation of coagulation function by rotation thromboelastometry in critically ill patients with severe COVID-19 pneumonia. J Thromb Thrombolysis 50:281-286. https://doi.org/10.1007/ s11239-020-02130-7

Publisher's note Springer Nature remains neutral with regard to jurisdictional claims in published maps and institutional affiliations. 